Journal of Advanced Research in Fluid Mechanics and Thermal Sciences

Journal homepage: www.akademiabaru.com/arfmts.html ISSN: 2289-7879

\title{
Experimental Study of Mixed Convection in a Cavity with a Rotating Cylinder
}

Keywords:

Heat transfer; turbulent flow; mixed convection; semi-circle enclosure; rotating cylinder

\section{ABSTRACT}

Mixed convection in a semi-circle enclosure of radius $0.15 \mathrm{~m}$ and length $0.75 \mathrm{~m}$ is studied experimentally. An insulated rotation cylinder is fixed at the center of the cavity to improve the heat transfer coefficient, the bottom wall of the enclosure is subjected to constant heat flux while the external curved wall is exposed to the ambient temperature. Cavity is placed horizontally and vertically and the angular velocities $(62.8,83.73,125.6) \mathrm{rad} / \mathrm{s}$. Results show an improvement of heat transfer coefficient with increasing angular velocity and with the horizontal and vertical cavity positioning.

\section{Introduction}

Heat transfer is considered alone of the challenges in engineering. The adding of heat to a system or the removing of heat from a system occurs in different ways, for example, removing of heat from computer chips or optical devices, cooling of systems for power plants, Refrigerators, indoor temperature control devices. The above heat transfer applications impact people's daily lives and support on the carried out of new research in order to enhance their efficiency [1]. The mixed convection phenomena take place when natural and forced convection mechanisms to act together. The classic problems of mixed convection heat transfer in a cavity have received considerable interest due to powerful relation to many practical's engineering utilization. A cavity model uses to simplify for numerous heat transfer issues. Many researchers presented with experimental and numerical investigation on various gaps for convection problems involving a rotating or stationary cylinder and the current study semicircle cavity. Ridouane et al., [2] studied numerically heat transfer in an isosceles triangular cavity. Rahman et al., [3] studied numerically the mixed convection flow inside vented square with a heat conducting horizontal solid circular cylinder located at the center of cavity.

\footnotetext{
* Corresponding author.

E-mail address: zenaselman0@gmail.com
}

https://doi.org/10.37934/arfmts.74.2.1626 
Rahman et al., [4] performed numerically mixed convection in two dimensions on a rectangular enclosure with heat source applied on the right vertical wall. Costa and Raimundo [5] studied the square cavity with a rotary cylinder positioned at the center. Brito et al., [6] presented numerical simulation of turbulent natural convection of air in a square enclosure with a localized heating source on the center of the horizontal bottom surface. Alshara et al., [7] investigated numerically for the effect of rotating horizontal single and multi cylinders on mixed convection heat transfer in an equilateral triangular enclosure. Salem [8] introduced an experimental study of impact of inclination angle on natural heat transfer in a rectangular cavity by uses the heat fluxes ranges $(4-108) \mathrm{w} / \mathrm{m}^{2}$, Rayleigh number $\left(1.9 \times 10^{5}-5 \times 10^{6}\right)$, inclination angles $(15-75)$ and mass flow rates $(0-0.062) \mathrm{kg} / \mathrm{sec}$ it can be shown that an improvement of Nussle number with increasing of the heat flux and the mass flow rate and also with increasing the inclination angle. Liao and Lin [9] studied mixed and free convection of a two-dimension square cavity that includes a stationary, or a rotating cylinder. Yasin et al., [10] investigated experimentally a study for heat transfer inside a cavity. Safari et al., [11] presented a numerical study of turbulent natural convection and laminar flow mixed convection of air flow was solved in a room. The infinite volume method was utilized to resolve governing differential equations for this flow. Karimi et al., [12] studied numerically the steady state mixed convection a round two heated horizontal cylinders in a two-dimensional square cavity. Aithal et al., [13] simulated turbulent fluid flow and thermal characteristics of natural convection induced by centrally located hot cylinder in cold square cavity numerically. Mohammed et al., [14] presented a numeric simulation of mixed convection in rectangular duct containing a baffle mounted on the wall. It has been demonstrated an improvement in the characteristics heat transfer with increasing the baffle height. Kareem and Gao [15] investigated numerically the combined forced and natural convection heat transfer in differentially heated three dimension obstructed cavity with a thermally insulated rotating circular cylinder Reynolds numbers were varied from (5000-30000). Norhaliza et al., [16] presented a numeric analysis with the existence of magnetic field for heat transfer in rectangular enclosure. This studied demonstrated as the effect of Hartmann number increases, the flow convection becomes weakened, and then the rate of heat transfer has reduced.

\section{Experimental Setup}

An experimental study was carried out in a semi-circle enclosure $(30 \times 15 \times 75 \mathrm{~cm})$ at Figure 1 shows a schematically diagram of the cavity. The Figure 2 illustrates the diagram of the practical device. Semi-circle container made of aluminum and based on a rectangular wooden box manufactured from wood and containing the insulator layer. Teflon cylinder located at cavity's center which is connected to an external motor to provide an angular velocity. An electrical heater was mounted on the bottom surface of the test section to provide a constant heat flux and placed inside a wooden cover. The local temperature of bottom wall of semicircle cavity was measured by collection of the thermocouple type and control measure include AC digital ammeter, $V C$ digital voltmeter used to measure the input voltage into heater ,Digital temperature gage used to convert the signal comes from thermocouples collation into measurable signal, Power controller it's DC power supply is set up to be measure power supply while variance is utilized as a secondary unit to ensure that input of electric power to heater be control. The bottom wall of the enclosure is undergone to constant heat flux, while the rotating cylinder located in the center of the cavity and external curved wall is exposed to the ambient temperature. The values of inclination angles used in this study are $\varnothing\left(0^{\circ}, 90^{\circ}\right)$ and the angular velocities $(62.8,83.73,125.6) \mathrm{rad} / \mathrm{s}$. 


\subsection{Processing the Experimental Data}

The measured value of net e.m.f by MultiMate between ice -bath and each thermocouple is substituted into Eq. (1) in order to determine the temperature measured by that thermocouple.

$\mathrm{T}_{\mathrm{L}}=\frac{V(\mathrm{v})}{0.041}+\mathrm{T}_{\infty}$

where local temperature along bottom wall, $T_{L}$, voltage reading from Multimater, $V$, environmental temperature, $T_{\infty}, 0.041$ : constant. The average temperature of the heated surface of the bottom wall can be computation as following in Eq. (2) where the value of hot wall temperature, $T_{s}$, and the number of thermocouples installed in the hot wall, $\mathrm{n}$. The angular speed of the roller is calculated as follows in Eq. (3) where the revaluation per mint, $N$. The heat flux along the heated surface can be calculated as [17] and the experimental cases the average Nusselt number in Eq. (4) where mean temperature of fluid, $T_{f}$, the voltage, $V$, current, I, and heated surface area, $A$. The Rayleigh number can be calculated as following in Eq. (5) where Gravitation acceleration, g, rate of change in of density with respect to the change in temperature, $B$, Hydraulic diameter, $D_{h}$, thermal conductivity, $k$, Thermal diffusivity of fluid, $\alpha$, and the kinematic viscosity, $u$.

$$
\begin{aligned}
& \overline{T S}=\frac{\sum T s}{n} \\
& \omega=\frac{2 \pi N}{60} \\
& N u_{a v}=\frac{q^{\prime \prime}}{k\left(T_{s}-T_{f}\right)} \\
& R a=\frac{g \beta q^{\prime \prime} D_{h}^{4}}{k v \alpha}
\end{aligned}
$$

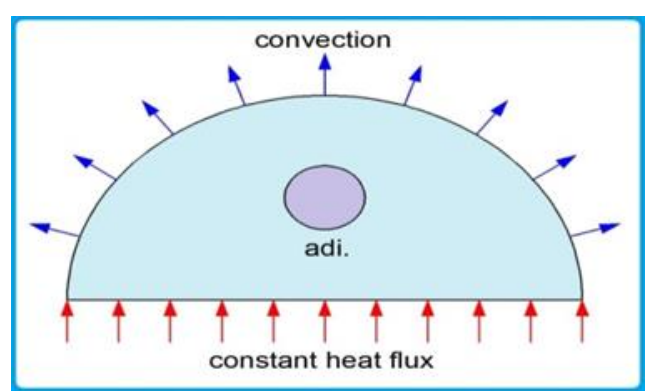

Fig. 1. Schematic diagram of cavity

These are properties from [18] and calculated from Eq. (6) at heat flux $290 \mathrm{~W} / \mathrm{m}^{2}$ corresponding Rayleigh number $2.9 * 10^{8}$ (Table 1 ).

Table 1

Properties of fluid at heat flux $290 \mathrm{~W} / \mathrm{m}^{2}$

\begin{tabular}{ll}
\hline Properties & Value(unit) \\
\hline $\mathrm{k}$ & $0.0278(\mathrm{~W} / \mathrm{m} . \mathrm{k})$ \\
$\alpha$ & $0.2537 * 10^{-4}\left(\mathrm{~m}^{2} / \mathrm{s}\right)$ \\
$\mathrm{u}$ & $17.80^{*} 10^{-6}\left(\mathrm{~m}^{2} / \mathrm{s}\right)$ \\
$\beta$ & $0.0031(1 / \mathrm{k})$ \\
\hline
\end{tabular}


$\mathrm{T}_{\text {pro }}=\frac{T_{S}-T_{f}}{n}$

These are properties from [18] and calculated from Eq. (6) at heat flux 540W/ $\mathrm{m}^{2}$ corresponding Rayleigh number $5^{*} 10^{8}$ (Table 2 ).

Table 2

Properties of fluid at heat flux $540 \mathrm{~W} / \mathrm{m}^{2}$

\begin{tabular}{ll}
\hline Properties & Value(unit) \\
\hline $\mathrm{k}$ & $0.0293(\mathrm{~W} / \mathrm{m} . \mathrm{K})$ \\
$\alpha$ & $0.028448^{*} 10^{-4}\left(\mathrm{~m}^{2} / \mathrm{s}\right)$ \\
$\mathrm{u}$ & $19.84 * 10^{-6}\left(\mathrm{~m}^{2} / \mathrm{s}\right)$ \\
$B$ & $0.00293(1 / \mathrm{K})$ \\
\hline
\end{tabular}

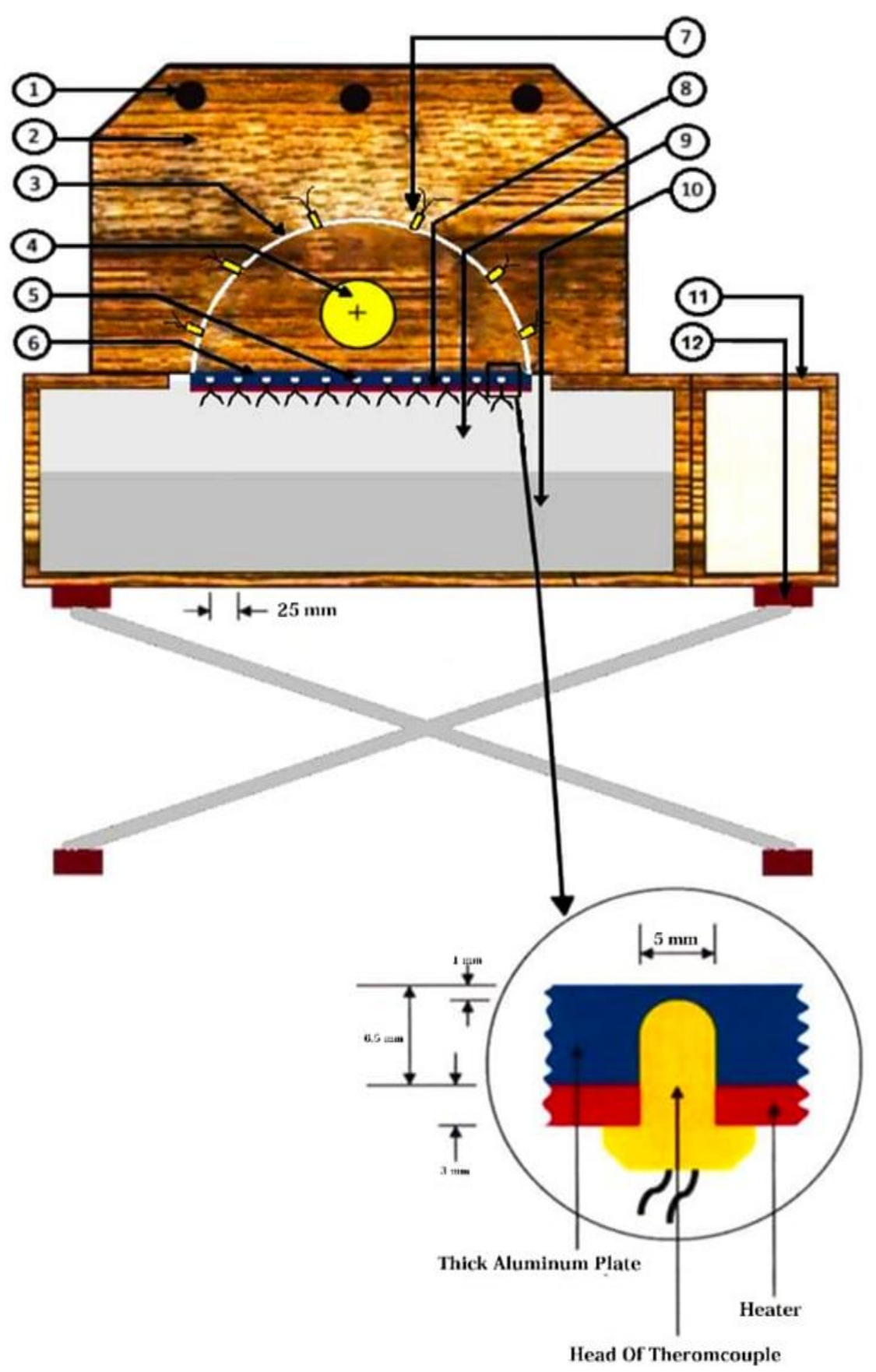

Fig. 2. Schematic of apparatus (transverse section) 

1) Fixing rod
2) Woodenportion
3) Aluminum enclosure
4) Teflon wall
5) Bottom wall
6) Thick plate
7) Thermocouple for curved walls
8) Heater
9) Ceramic fiber insulation
10) Reinforced thermal cork
11) Wooden chamber
12) Wooden board for inclination

\section{Results and Discussion}

The local Nusselt along the cavity of the lower wall has been used to help examining the experimental performance. The experimental results examined two values heat flux and angular velocity to show the effect of inclination angle.

\subsection{The Effect of Angular Velocity on Local Temperature}

Shows The effect of angular velocity for the solid cylinder on the temperature variation along the lower wall. Also, the figure shows the examined value of Rayleigh $\left(2.9 * 10^{8}\right)$ which corresponding to heat flux $q=290 \mathrm{w} / \mathrm{m}^{2}$ with a constant inclination angles and different angular velocity $\omega=62.8,83.73$, 125.6. From Figure 3 we can notice that at the inclination angle $\phi=0^{\circ}$ (horizontal situation) the temperature of the surface is high, and the distribution of the temperature along the cross-section of the hot surface it is observed with a little rising in the area under the rotary cylinder .The reason of this increasing is the resistance of heat transfer in the tight area under the cylinder. At $\varnothing=90^{\circ}$ (vertical situation) it is clearly observed that the temperature of the surface is lower compared with the horizontal situation. The reason behind that the impact of forced convection on the hot wall. Increasing heat flux $\mathrm{q}=540 \mathrm{w} / \mathrm{m}^{2}$ for Rayleigh number $\mathrm{Ra}=5^{*} 10^{8}$ with various angular velocity 62.8 , $83.73,125.6 \mathrm{rad} / \mathrm{s}$, at constant inclination angle $\varnothing=0^{\circ}$ it is important to observe the trend of temperature curves starts increasing, and then shows maximum peak at the distance $x=0.175 \mathrm{~m}$. The regular curves for a temperature along the heated surface of the cavity can be clearly observed a at constants inclination angle $\varnothing=90^{\circ}$. 

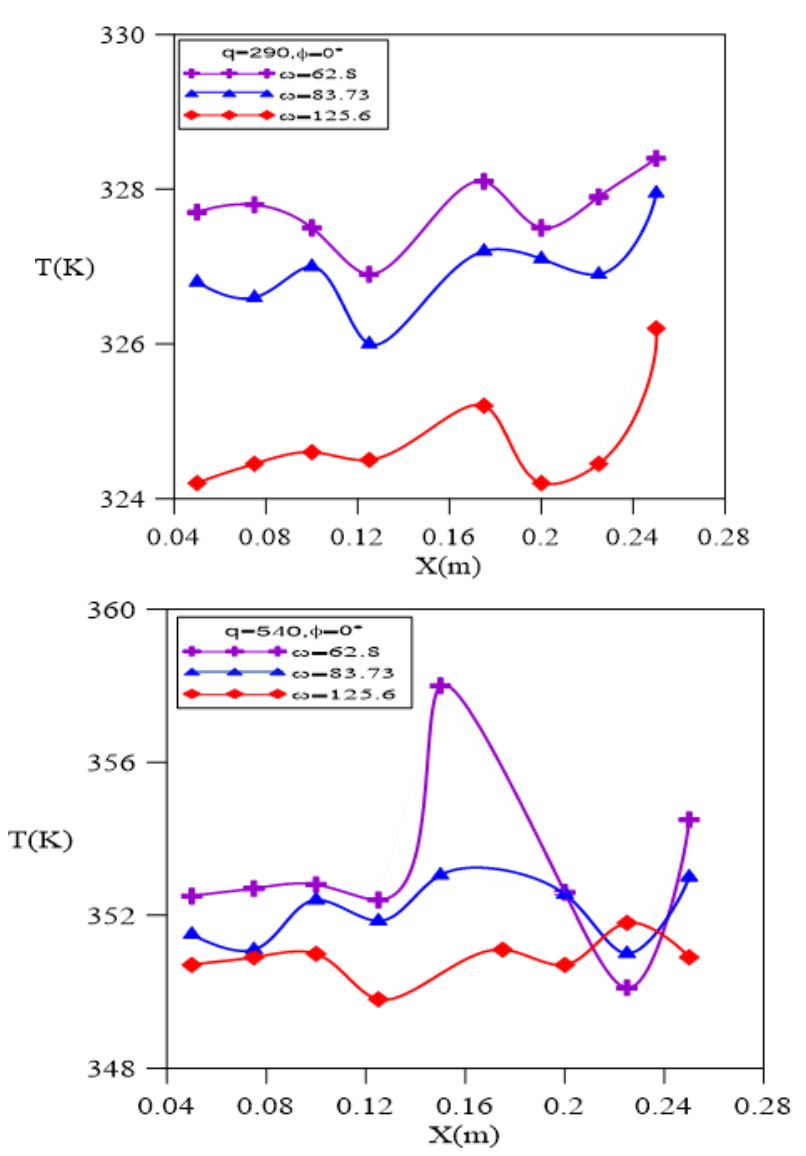
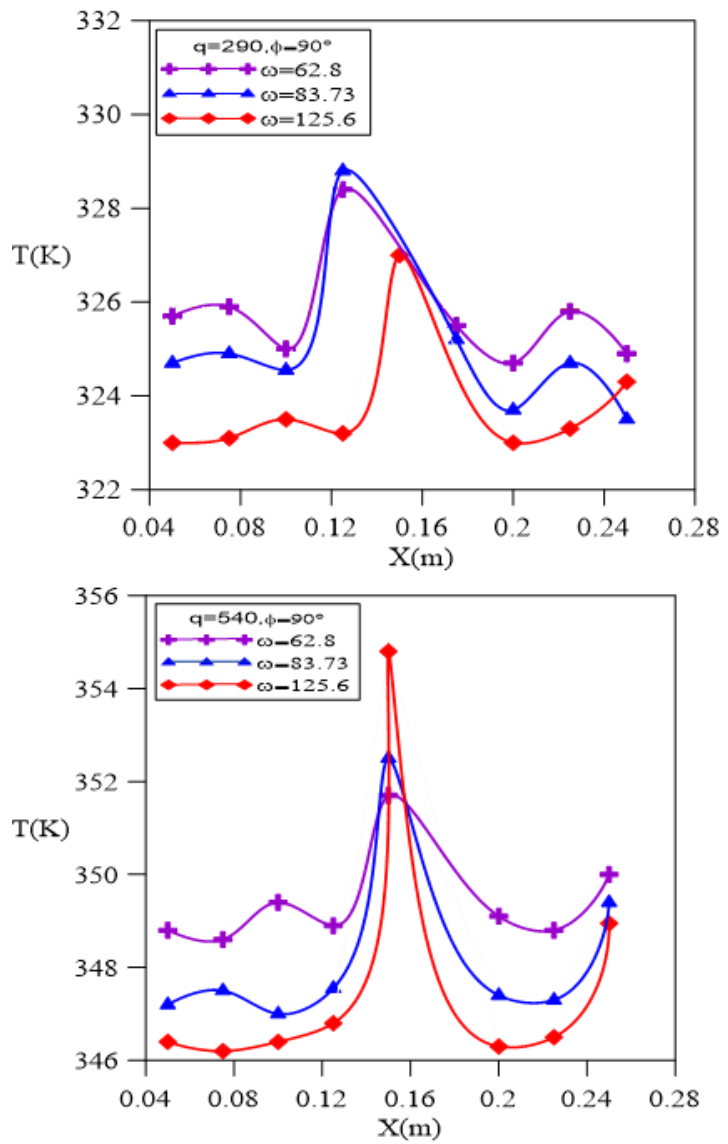

Fig. 3. Temperature distribution along bottom wall at heat flux $q=290 \mathrm{w} / \mathrm{m}^{2}$ and $540 \mathrm{w} / \mathrm{m}^{2}$ with different $\omega$ and $\varnothing=0^{\circ}, 90^{\circ}$

\subsection{Nusselt Number}

The variations of local Nusselt number are sketching along the heated lower wall for various inclination angles and angular velocities. Figure 4 shows the variation of experimental local Nusselt number with various angular velocities $\omega=62.8,83.73,125.6 \mathrm{rad} / \mathrm{s}$ at heat flux $\left(q=290 \mathrm{w} / \mathrm{m}^{2}\right)$ with a constant inclination angle $\left(0^{\circ}, 90^{\circ}\right)$. It is observed that at inclination angle $0^{\circ}$ the increasing of angular velocity leads to increase Nu. Also, Figure 4 shows the values of Nusselt number at the left side below the surface are higher than the values at right side, this is because of the buoyancy effect at the left side which is opposing to the air rotation motion and vice versa at the right side. Regarding $\varnothing=90^{\circ}$, it is observed at higher angular velocity, the Nusselt number is decreased at $\mathrm{x}=0.15 \mathrm{~m}$ which in turn decreasing the effect of forced convection in this area. Also, Figure 4 shows the impact of increasing heat flux to $540 \mathrm{w} / \mathrm{m}^{2}$ with angular velocity $62.8,83.73,125.6 \mathrm{rad} / \mathrm{s}$ in $\varnothing=90^{\circ}$, In addition, it shows a lower peak of the curves of Nu which occurs in the middle point of the heated surface in the area under the rotating cylinder due to flow resistance. For heat flux $540 \mathrm{w} / \mathrm{m}^{2}$ with inclination angle $\varnothing=0^{\circ}$, it can be observed the increasing Nusselt number with increasing angular velocity due to dominant of forced convection. 

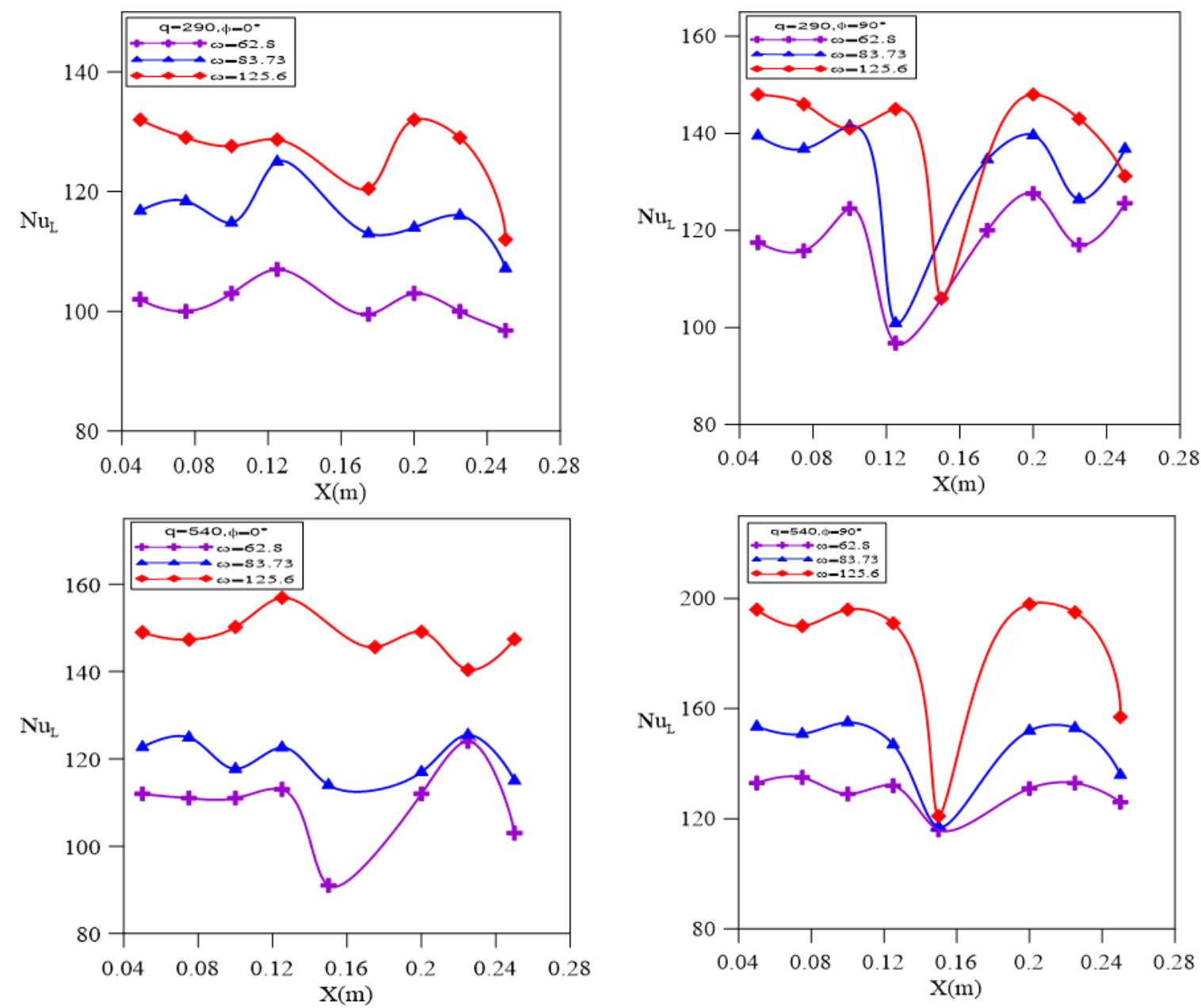

Fig. 4. Variation local of Nusselt number along the bottom wall at heat flux $q=290 \mathrm{w} / \mathrm{m}^{2}$ and 540 $\mathrm{w} / \mathrm{m}^{2}$ with different $\omega$ and $\varnothing=0,90$

Figure 5 shows $q=290 \mathrm{w} / \mathrm{m}^{2}$ and $\omega=62.8,83.73 \mathrm{rad} / \mathrm{s}$ which presents the variation of local Nusselt number at inclination angle for two cases $\varnothing=90^{\circ}$ the maximum summit for two curves local Nusselt number take place at two-points of distance $(x=0.1, x=0.2) \mathrm{m}$. reducing the values of Nusselt in the near middle of the heated surface due to increasing the resistance of convection heat transfer in this area. Due to increasing angular velocity $\omega=125.6 \mathrm{rad} / \mathrm{s}$ for $\varnothing=90^{\circ}$, then the values of Nusselt number decreasing the middle point, due to the change in the direction of buoyancy with the direction of the flow air. At heat flux $q=540 \mathrm{w} / \mathrm{m}^{2}$ and angular velocity $=62.8,83.73,125.6 \mathrm{rad} / \mathrm{s}$ with inclination angles $0^{\circ}, 90^{\circ}$ in Figure 5 illustrates the trend of the curves of local Nusselt number along the lower wall which decreasing at the middle surface, because of the increasing of convection heat transfer resistance at the end of the heated surface. At heat flux $540 \mathrm{w} / \mathrm{m}^{2}$ and angular velocity $125.6 \mathrm{rad} / \mathrm{s}$, the figure shows the maximum peak takes place at distance of $x=0.2 \mathrm{~m}$, and the difference in the distribution of Nusselt on both sides of the hot surface due to the difference in the direction of the buoyancy with the direction of air movement inside the cavity. 

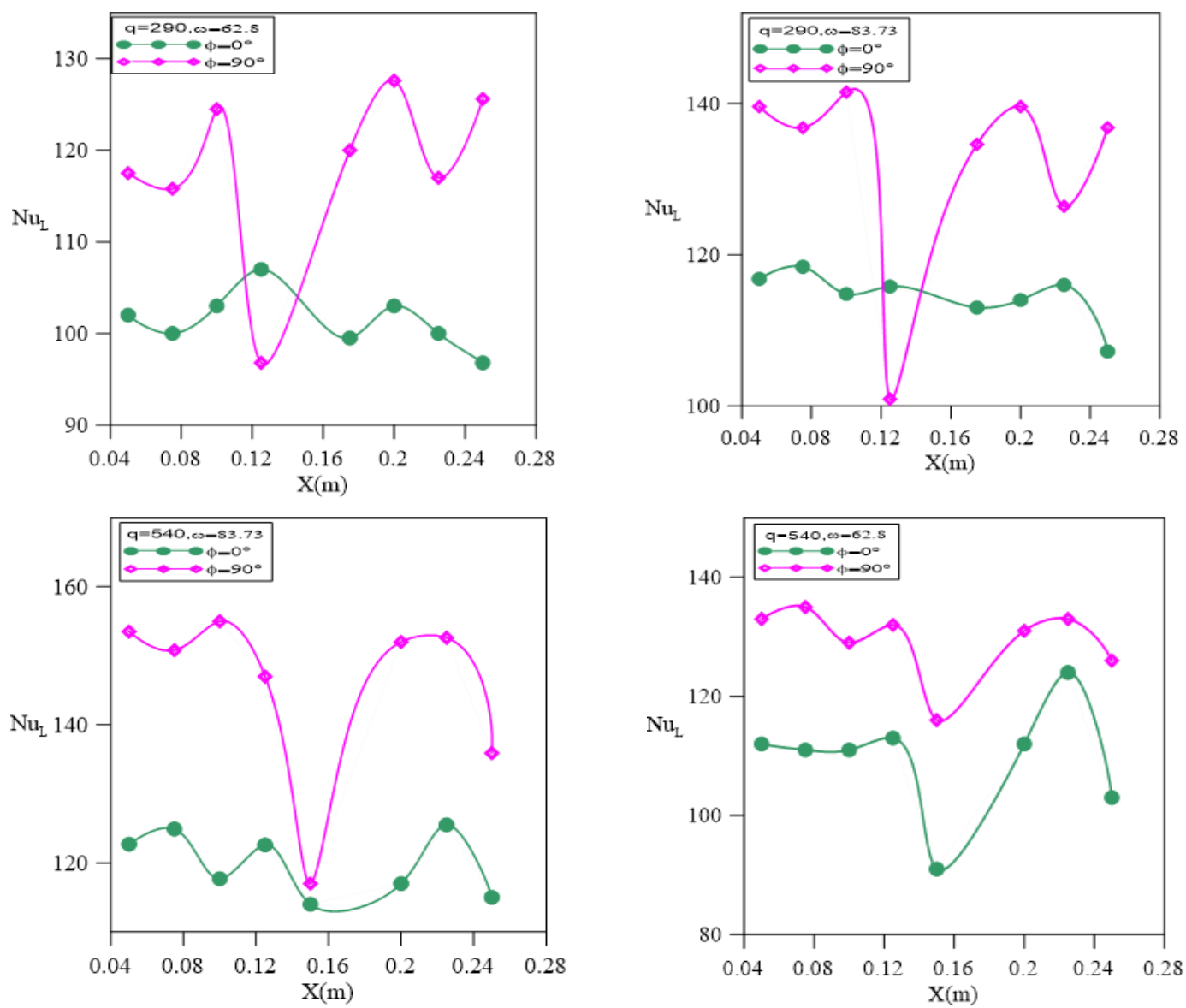

Fig. 5. Variation of local Nusselt number along the bottom wall at heat flux $q=290 \mathrm{w} / \mathrm{m}^{2}$ and $540 \mathrm{w} / \mathrm{m}^{2}$ with different $\varnothing$ and $\omega=62.8,83.73,125$

\subsection{The influence of inclination angle on local temperature}

Figure 6 shows the variation of local temperature distribution at the lower wall for two inclination angles at heat flux $\mathrm{q}=290 \mathrm{w} / \mathrm{m}^{2}$ and angular velocities $62.8,83.73,125.6 \mathrm{rad} / \mathrm{s}$ respectively. As observed results, for inclination angle $0^{\circ}$ the minimum value of temperature has occurred at $x=0.125 \mathrm{~m}$ with the perform of two angular velocity $\omega=62.8,83.73 \mathrm{rad} / \mathrm{s}$. At the angular velocity 125.6 the maximum value temperature has been occurred at $x=0.18$ for the inclination angle $0^{\circ}$. A maximum value of temperature occurs at midpoint, while, its minimum value of temperature occurs in the edge near the curved wall at angular velocity equal $62.8,83.73 \mathrm{rad} / \mathrm{s}$ when $\varnothing=90^{\circ}$. For the heat flux $q=540 \mathrm{w} / \mathrm{m}^{2}$ and $\omega=62.8 \mathrm{rad} / \mathrm{s}$ as in Figure 3 it is observed the local temperature distributions for inclination angles $0^{\circ}, 90^{\circ}$ thecurves will approach from each other. Also, shows the peak at a distance of $x=0.15$. If the angular velocity is $125.6 \mathrm{rad} / \mathrm{s}$, then, the values of local temperature for inclination angle $0^{\circ}$ is higher than the inclination angle $90^{\circ}$, and it shows that the maximum value of the temperature has occurred at a distance $x=0.15 \mathrm{~m}$, because of the influence of location for solid cylinder. 

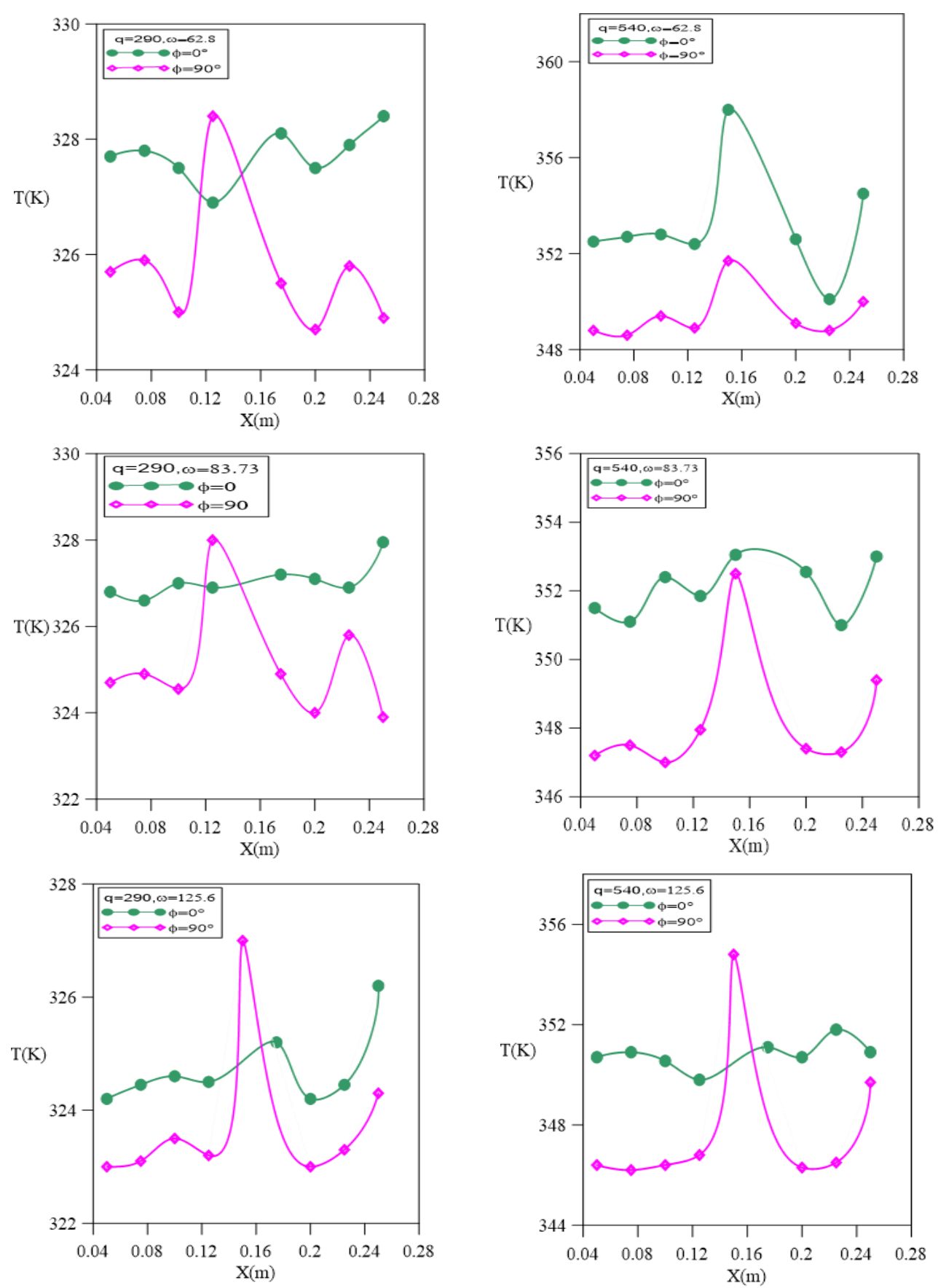

Fig. 6. Temperature distribution along bottom wall at heat flux $290 \mathrm{w} / \mathrm{m}^{2}$ and $540 \mathrm{w} / \mathrm{m}^{2}$ with different $\varnothing$ and $\omega=62.8,83.73,125.6 \mathrm{rad} / \mathrm{s}$

\section{Conclusions}

An experimental study of turbulent mixed convection heat Transfer of semi-circle cavity that contains a rotating cylinder has been completed at different rotational speeds, and inclination angle at horizontal and vertical. The present outcomes have displayed heat transfer enhancement in the enclosure can be summarized in below 
i. The heat transfer and fluid flow fields has increase with increasing of the rotational speeds which promotes local Nusselt number at the high values of the angular velocity and high Reynold's numbers

ii. It is observed that the maximum average Nusselt number occurred at angle $90^{\circ}$. Because of increasing the heat transfer rate occurs at increment the inclination angle.

iii. For both heat flux 290 and $540 \mathrm{~W} / \mathrm{m}^{2}$ and angular velocity equals to $62.8 \mathrm{rad} / \mathrm{s}$ the situation is better which increases the heat transfer by the mixed convection of the cavity is the inclination angle $\varnothing=30^{\circ}$ and $90^{\circ}$. While the high angular velocity of $(83.73 \mathrm{rad} / \mathrm{s}$ and $125.6 \mathrm{rad} / \mathrm{s})$ for both heat flux values where the most appropriate position for increasing heat transfer is with a tilt angle of $90^{\circ}$.

\section{References}

[1] Omranian, Seyed Ali. "The computation of turbulent natural convection flows." PhD diss., University of Manchester, 2011.

[2] Campo, Antonio, and Mohammed Hasnaoui. "Turbulent natural convection in an air-filled isosceles triangular enclosure." International Journal of Heat and Fluid Flow 27, no. 3 (2006): 476-489. https://doi.org/10.1016/i.ijheatfluidflow.2005.10.013

[3] Rahman, Mustafizur, M. A. Alim, Suman Saha, and M. K. Chowdhury. "Mixed convection in a vented square cavity with a heat conducting horizontal solid circular cylinder." Journal of naval architecture and marine engineering 5 , no. 2 (2008): 37-46. https://doi.org/10.3329/jname.v5i2.2504

[4] Rahman, Md M., M. A. Alim, and M. A. H. Mamun. "Finite element analysis of mixed convection in a rectangular cavity with a heat-conducting horizontal circular cylinder." Nonlinear Analysis: Modelling and Control 14, no. 2 (2009): 217-247.

https://doi.org/10.15388/NA.2009.14.2.14522

[5] Costa, V. A. F., and A. M. Raimundo. "Steady mixed convection in a differentially heated square enclosure with an active rotating circular cylinder." International Journal of Heat and Mass Transfer 53, no. 5-6 (2010): 1208-1219. https://doi.org/10.1016/i.ijheatmasstransfer.2009.10.007

[6] Brito, Rogerio Fernandes, Genésio José Menon, and Marcelo José Pirani. "Turbulent natural convection in enclosures using large-eddy simulation with localized heating from horizontal bottom surface and cooling from vertical surfaces." Journal of the Brazilian Society of Mechanical Sciences and Engineering 31, no. 3 (2009): 199209.

https://doi.org/10.1590/S1678-58782009000300005

[7] Alshara, Ahmed KM. "Effect Of Single Or Multi Rotating Horizontal Cylinders On The Mixed Convection Heat Transfer Inside A Triangular Enclosure." Al-Qadisiyah Journal for Engineering Sciences 5, no. 1 (2012): 95-110.

[8] Salem, Thamer Khalif. "The influence of inclination angle on natural convection in a rectangular enclosure." Academic Research International 4, no. 2 (2013): 111.

[9] Liao, Chuan-Chieh, and Chao-An Lin. "Mixed convection of a heated rotating cylinder in a square enclosure." International Journal of Heat and Mass Transfer 72 (2014): 9-22. https://doi.org/10.1016/j.ijheatmasstransfer.2013.12.081

[10] Abdulla, Ayad S., Dhia Al-Deen H. Alwan, and Nabil J. Yasin. "Experimental Study of Mixed Convection in an Enclosure with a Cold Movable Top Wall and Hot Bottom Wall." Al-Khwarizmi Engineering Journal 10, no. 1 (2014): $32-46$.

[11] Safaei, Mohammad, Marjan Goodarzi, and Mohammadali Mohammadi. "Numerical modeling of turbulence mixed convection heat transfer in air filled enclosures by finite volume method." The International Journal of Multiphysics 5, no. 4 (2011). https://doi.org/10.1260/1750-9548.5.4.307

[12] Karimi, Fariborz, Hongtao Xu, Zhiyun Wang, Mo Yang, and Yuwen Zhang. "Numerical simulation of steady mixed convection around two heated circular cylinders in a square enclosure." Heat Transfer Engineering 37, no. 1 (2016): 64-75. https://doi.org/10.1080/01457632.2015.1042343

[13] Aithal, S. M. "Turbulent natural convection in a square cavity with a circular cylinder." Journal of Thermophysics and Heat Transfer 30, no. 4 (2016): 843-853.

https://doi.org/10.2514/1.T4873 
[14] Mohammed, H., O. Alawi, and NA Che Sidik. "Mixed convective nanofluids flow in a channel having forward-facing step with baffle." Journal of Advanced Research in Applied Mechanics 24, no. 1 (2016): 1-21.

[15] Kareem, Ali Khaleel, and Shian Gao. "Mixed convection heat transfer of turbulent flow in a three-dimensional liddriven cavity with a rotating cylinder." International Journal of Heat and Mass Transfer 112 (2017): 185-200. https://doi.org/10.1016/j.ijheatmasstransfer.2017.04.118

[16] Bakar, Norhaliza Abu, Rozaini Roslan, and Arash Karimipour. "Magnetic Field Effect on Mixed Convection Heat Transfer in a Lid-Driven Rectangular Cavity." CFD Letters 12, no. 1 (2020): 13-21.

[17] Theraja, B. L. A Textbook of Electrical Technology (Volume-ii). Ram Nagar, 1997.

[18] Holman, Jack Philip. Heat Transfer-Si Units-Sie. Tata McGraw-Hill Education, 2002. 